\title{
KHẢO SÁT CHỨC NĂNG TUYẾN GIÁP Ở PHỤ NŨ̉ VÔ SINH
}

Nguyễn Thị Phuơng ${ }^{1}$, Vũ Bích Nga ${ }^{2}$

1. Bệnh viện Đa khoa tỉnh Ninh Bình

2. Bệnh viện Đại học Y Hà Nội

DOI: $10.47122 / v j d e .2020 .41 .15$

\section{ABSTRACT \\ Survey of thyroid function in infertile women}

Objectives: To determine the incidence of thyroid dysfunction in infertile women and comment on some factors related to thyroid dysfunction in infertile women. Methods: Study subjects were 222 infertile women (age 18-45) who were surveyed to test FT4, TSH. Relevant factors to be investigated included age, BMI, histories of lousy obstetrics include miscarriage or stillbirth, menstrual status, length of infertility, and blood prolactin levels. Thyroid dysfunction was assessed based on TSH levels above or below the normal reference range (TSH: 0.45 - 4.12) according to ATA 2012. Results: The rate of thyroid dysfunctionin the study patient group was $12.7 \%$. The incidence of hyperthyroidism was $3.2 \%$, including $0.5 \%$ of clinical hyperthyroidism and $2.7 \%$ of subclinical hyperthyroidism. The incidence of hypothyroidism was $9.5 \%$, including $0.5 \%$ of clinical hypothyroidism and $9.0 \%$ subclinical hypothyroidism. The incidence of thyroid dysfunction was higher in the group of older women. The rate of thyroid dysfunction in the group over 35 years old $(5.4 \%)$ was higher than the women group under 25 years old $(1.4 \%)$. The proportion of infertile women who had menstrual disorders was $32.7 \%$. In which patients with thyroid dysfunction make up $4.6 \%$, patients with normal thyroid functionwas $28.1 \%$. In $4.6 \%$ of patients with thyroid dysfunction, the rate of menstrual disorders was $37 \%$ that was higher than in patients with normal thyroid function $(28.1 \%)$. The rate of hyperprolactinemia in the study group was $24.4 \%$ (patients with thyroid dysfunction accounted for 5.9\%; patients who have normal thyroid function accounted for $18.5 \%$ ). In patients with thyroid dysfunction, the rate of increased prolactin levels in the blood $(46.4 \%)$ was higher than that of the euthyroid group $(21.1 \%)$. The proportion of patients with histories of lousy obstetrics include miscarriage and stillbirth in the study was $31.1 \%$ (15.3\% had a history of miscarriage, $9.9 \%$ had a history of stillbirth, $5.9 \%$ had both a history of miscarriage and stillbirth). Conclusions: In ourstudy: The rate of thyroid dysfunction in the study subjects was $12.7 \%$. The incidence of thyroid dysfunction was higher in the 35 over age group. The proportion of infertile women with menstrual disorders or hyperprolactinemia was higher in the group that had the thyroid dysfunction than in the group hadregular thyroid function.

Key words: thyroid function, infertile women

\section{TÓM TẮT}

Mục tiêu: Xác định tỷ lệ rối loạn chức năng tuyến giáp ở phụ nữ vô sinh và nhận xét một số yếu tố liên quan đến rối loạn chức năng tuyến giáp ở phụ nữ vô sinh. Phương pháp: Đối tượng nghiên cứu là 222 phụ nữ vô sinh (tuổi từ 18 - 45) được khảo sát làm xét nghiệm FT4, TSH. Yếu tố liên quan được khảo sát gồm: tuổi, BMI, tiền sử sản khoa xấu gồm thai lưu hoặc xảy thai, tình trạng kinh nguyệt, thời gian vô sinh, mức prolactin máu. Tình trạng rối loạn chức năng tuyến giáp được đánh giá dựa trên mức TSH trên hoặc dưới khoảng tham chiếu bình thường (TSH: $0,45-4,12)$ theo ATA 2012. Kết quả: Tỷ lệ rối loạn chức năng tuyến giáp trên nhóm bệnh nhân nghiên cứu là $12.7 \%$. Tỷ lệ cường giáp là $3.2 \%$ gồm $0.5 \%$ cường giáp lâm sàng và $2.7 \%$ cường giáp dưới lâm sàng. Tỷ lệ suy giáp là $9.5 \%$ gồm $0.5 \%$ suy giáp lâm sàng và $9.0 \%$ suy giáp cận lâm sàng. Tỷ lệ rối loạn chức năng tuyến giáp tăng cao hơn ở nhóm phụ nữ lớn tuổi. Tỷ lệ rối loạn chức năng 
tuyến giáp ở nhóm trên 35 tuổi (chiếm 5.4\%) cao hơn nhóm phụ nữ dưới 25 tuổi (1.4\%).Tỷ lệ phụ nữ có tình trạng rối loạn kinh nguyệt là $32.7 \%$, trong đó $\mathrm{BN}$ rối loạn chức năng tuyến giáp chiếm $4.6 \%$ và bệnh nhân bình giáp chiếm $28.1 \%$. ở $4.6 \%$ bệnh nhân rối loạn chức năng tuyến giáp giáp thì tỷ lệ rối loạn kinh nguyệt là $37 \%$ cao hơn nhóm bệnh nhân bình giáp ( $28.1 \%)$. Tỷ lệ tăng mức prolactin máu của nhóm nghiên cứu là $24.4 \%$ (bệnh nhân có rối loạn chức năng tuyến giáp chiếm $5.9 \%$ và bệnh nhân bình giáp chiếm $18.5 \%$ ). ở những bệnh nhân có rối loạn chức năng tuyến giáp thì tỷ lệ tăng mức prlactin máu (46.4\%) cao hơn nhóm bình giáp (21.1\%). Tỷ lệ bệnh nhân có tiền sử sản khoa xấu bao gồm xảy thai, thai lưu trong nghiên cứu là $31.1 \%$. $(15.3 \%$ có tiền sử sảy thai, $9.9 \%$ có tiền sử thai lưu, $5.9 \%$ có cả tiền sử xảy thai và thai lưu). Kết luận: Tỷ lệ rối loạn chức năng tuyến giáp ở nhóm bệnh nhân nghiên cứu là $12.7 \%$. Tỷ lệ rối loạn chức năng tuyến giáp tăng cao hơn ở nhóm tuổi trên 35 . Tỷ lệ phụ nữ vô sinh có tình trạng rối loạn kinh nguyệt hoặc tăng mức prolactin máu ở nhóm rối loạn chức năng tuyến giáp thì cao hơn so với nhóm phụ nữ vô sinh bình giáp.

Tù khóa:Chức năng tuyến giáp, phu nũ vố inh

Chịu trách nhiệm chính: Vũ Bích Nga

Ngày nhận bài: 12/8/2020

Ngày phản biện khoa học: 15/9/2020

Ngày duyệt bài: 17/10/2020

Email: vubichnga116@gmail.com

Điện thoại: 0913544622

\section{1. ĐẶT VẤN ĐỀ}

Vô sinh đang là một trong những vấn đề nan giảicủa xã hội hiện đại ngày nay, là nỗi lo lắng và sợ hãi của rất nhiều cặp vợ chồng. Có nhiều nguyên nhân dẫn đến vô sinh, một trong những nguyên nhân đó là bất thường về chức năng tuyến giáp. Tỷ lệ vô sinh nguyên phát hoặc thứ phát liên quan đến cường giáp đã được mô tả là $0,9 \%$ đến $5,8 \%$. Tỷ lệ mắc suy giáp ở nhóm tuổi sinh sản $2-4 \%$, được cho là một trong những nguyên nhân quan trọng gây vô sinh và hỏng thai [1], [2]. Rối loạn chức năng tuyến giáp có thể dễ dàng xác định bằng xét nghiệm. Ở Việt Nam những năm gần đây, vấn đề rối loạn chức năng tuyến giáp trên phụ nữ vô sinh đã được quan tâm nhiều hơn, tuy nhiên vẫn còn nhiều tranh cãi về việc có nên sàng lọc tuyến giáp trên phụ nữ vồ sinh hay không. Các dữ liệu về chức năng tuyến giáp ở phụ nữ vô sinh cũng như hậu quả và các mối liên quan của nó vẫn còn hạn chế nên tôi tiến hành nghiên cứu đề tài: "Khảo sát chức năng tuyến giáp ở phụ nữ vô sinh" với hai mục tiêu sau:

1. Xác định tỷ lệ rối loạn chức năng tuyến giáp ở phu nũ vô sinh.

2. Nhận xét một số yếu tố liên quan đến rối loạn chức năng tuyến giáp ở phu nữ vô sinh.

\section{2. ĐỐI TƯợng VÀ PHƯƠNG PHÁP NGHIÊN CÚU}

\section{1. Đối tượng nghiên cứu}

221 Bệnh nhân $(\mathrm{BN})$ được chẩn đoán vô sinh đến khám và điều trị tại Trung tâm hỗ trợ sinh sản và mô ghép Bệnh viện Trường Đại học Y Hà Nội và Trung tâm Hỗ trợ sinh sản quốc gia Bệnh viện Phụ sản Trung ương từ tháng 01 năm 2018 đến tháng 8 năm 2020.

\subsubsection{Tiêu chuẩn lựa chọn $B N$ :}

- Nữ vô sinh, tuổi 18 - 45, đồng ý tham gia nghiên cứu.

- BN được chẩn đoán vô sinh theo Hội Y học sinh sản Hoa Kỳ ARSM[3].

- Không ở trong nhóm tiêu chuẩn loại trừ đối tượng nghiên cứu.

\subsubsection{Tiêu chuẩn loại trù̀ $B N$}

- $\mathrm{BN}$ hay người đại diện của $\mathrm{BN}$ không đồng ý tham gia nghiên cứu.

- BN đã xác định được các nguyên nhân thực thể gây vô sinh như: tắc nghẽn ống dẫn trứng cả hai bên, lạc nội mạc tử cung, lao sinh dục, $\operatorname{HIV}(+)$, giang mai, viêm vùng chậu, viêm phần phụ giai đoạn chưa ổn định và đang phải điều trị thuốc.

- BN mắc một số bệnh nội khoa như: viêm gan virus đợt tiến triển đang phải điều trị, suy gan, suy thận nặng, suy tim nặng, đái tháo đường kiểm soát đường máu kém.

- Đang mắc các bệnh cấp tính. Đang sử dụng các thuốc corticoid hoặc chế phẩm có 
chứa iodin, dopamine, heparin, estrogen, phenytoin, androgen, furosemide liều cao...

- Hồ sơ bệnh án không đầy đủ, bệnh nhân không được làm xét nghiệm yêu cầu của nghiên cứu.

\subsection{Phương pháp nghiên cứu:}

Mô tả cắt ngang và hồi cứu.

\subsection{Phương pháp thu thập số liệu}

- BN được khám lâm sàng và làm xét nghiệm FT4, TSH, Prolactin (đối với $\mathrm{BN}$ khám mới) hoặc từ Hồ sơ bệnh án (đối với $\mathrm{BN}$ hồi cứu đã điều trị tại Trung tâm trong thời gian nghiên cứu).

- Tiến hành thu thập thông tin theo mẫu bệnh án nghiên cứu.

- Tiêu chuẩn chẩn đoán cường giáp lâm sàng (LS), cường giáp dưới lâm sàng (DLS), suy giáp LS, suy giáp DLS theo ATA/AACE 2012.

2.4. Xử lý và phân tích số liệu: Theo phần mềm SPSS 25.0

\section{KẾT QUẢ NGHIÊN CÚU}

\section{1. Đặc điểm chung của nhóm $B N$ nghiên cứu}

Bảng 1. Đặc điểm chung của nhóm BN nghiên cứu.

\begin{tabular}{|c|c|c|}
\hline Tuổi & N & \% \\
\hline$<25$ tuổi & 26 & 11,7 \\
\hline $25-29$ tuối & 86 & 38,7 \\
\hline $30-34$ tuồi & 64 & 28,8 \\
\hline$\geq 35$ tuối & 46 & 20,5 \\
\hline Tống & 222 & 100 \\
\hline Mean \pm SD (tuối) & \multicolumn{2}{|c|}{$30,1 \pm 5,06$} \\
\hline Min - Max (tuồi) & \multicolumn{2}{|c|}{$18-45$} \\
\hline
\end{tabular}

Tuổi trung bình của các $\mathrm{BN}$ trong nghiên cứu là 30,1+5.06. Nhóm tuổi $25-29$ chiểm tỷ lệ cao nhất $(38,7 \%)$. Nhóm tuổi< 25 chiếm tỷ lệ thấp nhất $(11,7 \%)$.

\subsection{Tỷ lệ rối loạn chức năng tuyến giáp của $\mathrm{BN}$ nghiên cứu}

Biểu đồ 1. Tỷ lệ rối loạn chức năng tuyến giáp của nhóm $\mathrm{BN}$ nghiên cứu:

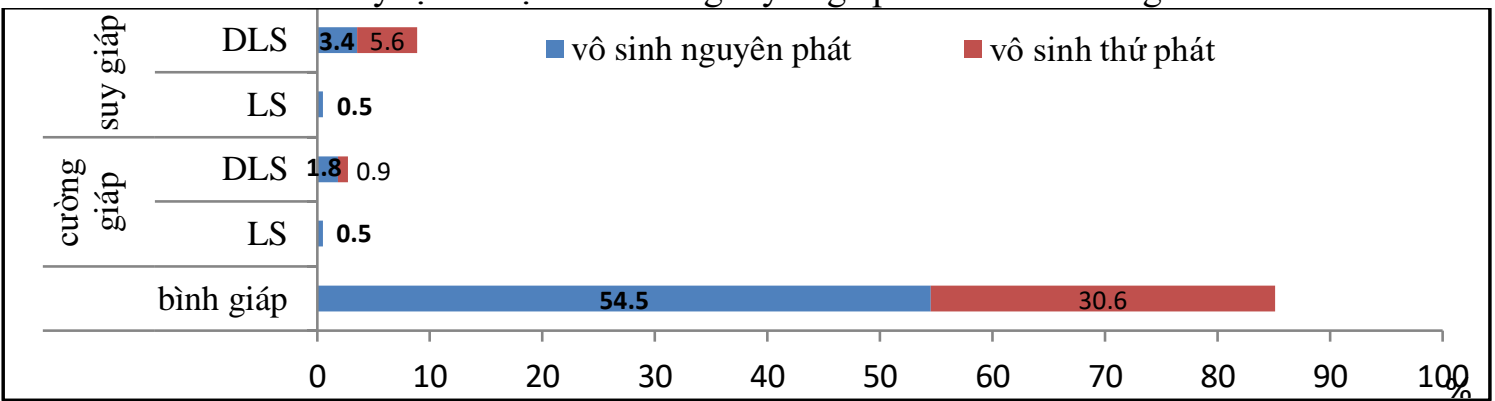

28/222 BN nghiên cứu có rối loạn chức năng tuyến giáp, chiếm 12,7\%. Trong đó cường giáp có $7 \mathrm{BN}$ chiếm $3,2 \%(01 \mathrm{BN}$ cường giáp LS chiếm $0.5 \%$ và $6 \mathrm{BN}$ cường giáp DLS chiếm $2.7 \%)$ và $21 \mathrm{BN}$ suy giáp chiếm $9,5 \%(01 \mathrm{BN}$ suy giáp $\mathrm{LS}$ chiếm $0,5 \%$ và $20 \mathrm{BN}$ suy giáp DLS chiếm $9 \%)$.

\subsection{Mối tương quan giữa chức năng tuyến giáp và một số yếu tố}

Bảng 2. Mối tương quan giữa chức năng tuyến giáp và tuổi

\begin{tabular}{|l|c|c|c|c|c|c|c|c|}
\hline \multirow{2}{*}{ Tuổi Chức năng TG } & \multicolumn{2}{|c|}{ Bình giáp } & \multicolumn{2}{c|}{ Cường giáp } & \multicolumn{2}{c|}{ Suy giáp } & \multicolumn{2}{c|}{ Chung } \\
\cline { 2 - 9 } & $\mathbf{n}$ & $\mathbf{\%}$ & $\mathbf{n}$ & $\mathbf{\%}$ & $\mathbf{n}$ & $\mathbf{\%}$ & $\mathbf{N}$ & $\mathbf{\%}$ \\
\hline$<25$ tuối & 23 & 10,4 & 0 & 0,0 & 3 & 1,4 & 26 & 11,7 \\
\hline
\end{tabular}




\begin{tabular}{|l|c|c|c|c|c|c|c|c|}
\hline \multirow{2}{*}{ Tuổi Chức năng TG } & \multicolumn{2}{|c|}{ Bình giáp } & \multicolumn{2}{|c|}{ Cường giáp } & \multicolumn{2}{c|}{ Suy giáp } & \multicolumn{2}{c|}{ Chung } \\
\cline { 2 - 9 } & $\mathbf{n}$ & $\mathbf{\%}$ & $\mathbf{n}$ & $\mathbf{\%}$ & $\mathbf{n}$ & $\mathbf{\%}$ & $\mathbf{N}$ & $\mathbf{\%}$ \\
\hline $25-29$ tuổi & 79 & 35,6 & 4 & 1,8 & 2 & 1,4 & 86 & 38,7 \\
\hline $30-34$ tuổi & 58 & 26,1 & 1 & 0,5 & 5 & 2,3 & 64 & 28,8 \\
\hline$\geq 35$ tuổi & 34 & 15,3 & 2 & 0,9 & 10 & 4,5 & 46 & 20,7 \\
\hline Tồng & 194 & 87,4 & 7 & 3,2 & 21 & 9,5 & 222 & 100 \\
\hline
\end{tabular}

Nhóm tuổi trên 35 có tỷ lệ rối loạn chức năng tuyến giáp cao nhất (chiếm $5,4 \%$ ). Nhóm tuổi dưới 25 có tỷ lệ rối loạn chức năng tuyến giáp ít nhất (chiếm 1,4\%).

Bảng 3. Mối tương quan giữa chức năng tuyến giáp và tình trạng kinh nguyệt.

\begin{tabular}{|l|c|c|c|c|c|c|c|c|}
\hline \multirow{2}{*}{ Kinh nguyệt } & \multicolumn{2}{c|}{ Bình giáp } & \multicolumn{2}{c|}{ Cường giáp } & \multicolumn{2}{c|}{ Suy giáp } & \multicolumn{2}{c|}{ Chung } \\
\cline { 2 - 9 } & $\mathbf{n}$ & $\mathbf{\%}$ & $\mathbf{n}$ & $\mathbf{\%}$ & $\mathbf{n}$ & $\mathbf{\%}$ & $\mathbf{n}$ & $\mathbf{\%}$ \\
\hline Đều & 131 & 59,6 & 6 & 2,7 & 11 & 5,0 & 148 & 67,3 \\
\hline Không đều & 62 & 28,1 & 1 & 0,5 & 9 & 4,1 & 72 & 32,7 \\
\hline Tồng & 193 & 87,8 & 7 & 3,2 & 20 & 9,1 & 220 & 100 \\
\hline
\end{tabular}

Tỷ lệ rối loạn kinh nguyệt ở nhóm $\mathrm{BN}$ nghiên cứu là $32.7 \%$, trong đó $\mathrm{BN}$ có rối loạn chức năng tuyến giáp chiếm $4,6 \%$ và $\mathrm{BN}$ bình giáp chiếm $28.1 \%$.

Tỷ lệ rối loạn kinh nguyệt trong nhóm $\mathrm{BN}$ rối loạn chức năng tuyến giáp (10/27 BN chiếm $37 \%$ ) cao hơn nhóm $\mathrm{BN}$ bình giáp (62/193 $\mathrm{BN}$ chiếm 32.1\%).

Bảng 4. Mối liên quan giữa chức năng tuyến giáp và tiền sử sản khoa xấu

\begin{tabular}{|l|c|c|c|c|c|c|c|c|}
\hline \multirow{2}{*}{ Tiền sử Chức năng TG } & \multicolumn{2}{|c|}{ Bình giáp } & \multicolumn{2}{c|}{ Cường giáp } & \multicolumn{2}{c|}{ Suy giáp } & \multicolumn{2}{c|}{ Chung } \\
\cline { 2 - 10 } & $\mathbf{n}$ & $\mathbf{\%}$ & $\mathbf{n}$ & $\mathbf{\%}$ & $\mathbf{n}$ & $\mathbf{\%}$ & $\mathbf{N}$ & $\mathbf{\%}$ \\
\hline Sảy thai & 28 & 12.6 & 1 & 0.5 & 5 & 2.2 & 34 & 15,3 \\
\hline Thai lưu & 16 & 7.2 & 0.0 & 0.0 & 6 & 2.7 & 22 & 9,9 \\
\hline $\begin{array}{l}\text { Không có tiền sử sản } \\
\text { khoa nặng nề }\end{array}$ & 154 & 69.4 & 6 & 2.7 & 13 & 5.8 & 173 & 77,9 \\
\hline
\end{tabular}

Có $77.9 \%$ BN nghiên cứu không có tiền sử sản khoa nặng nề. 31.1\% BN nhóm $\mathrm{BN}$ nghiên cứu có tiền sử sản khoa xấu là sảy thai, thai lưu $(15,3 \% \mathrm{BN}$ có tiền sử sảy thai, $9,9 \% \mathrm{BN}$ có tiền sử thai lưu và $5,9 \% \mathrm{BN}$ có cả xảy thai và thai lưu).

Bảng 5. Mối tương quan giữa chức năng tuyến giáp và mức Prolactin

\begin{tabular}{|c|c|c|c|c|c|c|c|c|}
\hline \multirow{2}{*}{$\begin{array}{l}\text { Chức năng TG } \\
\text { Prolactin }\end{array}$} & \multicolumn{2}{|c|}{ Bình giáp } & \multicolumn{2}{|c|}{ Suy giáp } & \multicolumn{2}{|c|}{ Cường giáp } & \multicolumn{2}{|c|}{ Chung } \\
\hline & $\mathbf{n}$ & $\%$ & $\mathbf{n}$ & $\%$ & $\mathbf{n}$ & $\%$ & $\mathbf{n}$ & $\%$ \\
\hline Bình thường & 151 & 68 & 10 & 4,5 & 5 & 2,3 & 166 & 74,7 \\
\hline $\mathrm{CaO}$ & 41 & 18,5 & 11 & 5,0 & 2 & 0,9 & 54 & 24,4 \\
\hline Thấp & 2 & 0,9 & 0,0 & 0,0 & 0,0 & 0,0 & 2 & 0,9 \\
\hline Tống & 194 & 87,4 & 21 & 9,5 & 7 & 3,2 & 222 & 100 \\
\hline
\end{tabular}

Có 24,4\% BN nhóm nghiên cứu có tăng mức prolactin máu trong đó BN rôi loạn chức năng tuyến giáp $5,9 \%(13 \mathrm{BN})$.

\section{BÀN LUẬN}

4.1. Đặc điểm chung của nhóm $\mathrm{BN}$ nghiên cứu:

Tuổi trung bình của các bệnh nhân trong nghiên cứu là $30,1 \pm 5,6$. Có lẽ ở lứa tuổi này tỷ lệ vô sinh tăng hơn do các rối loạn nội tiết của phụ nữ thường bắt đầu ở lứa tuổi này.

\subsection{Tỷ lệ rối loạn chức năng tuyến giáp} ở nhóm BN nghiên cứu

Tỷ lệ rối loạn chức năng tuyến giáp của nhóm $\mathrm{BN}$ nghiên cứu là $12,7 \%$, gồm cường giáp $3,2 \%$ và suy giáp là $9,5 \%$. Kết quả 
nghiên cứu của chúng tôi tương tự nghiên cứu của Canaris GJ (trên 25.862 người ở tiểu bang Colorado cho tỷ lệ nồng độ TSH tăng cao $9,5 \%$ và tỷ lệ $\mathrm{TSH}$ giảm là $2,2 \%$ với phạm vi bình thường của TSH 0,3-5,1 mIU / L ) [4]. và cao hơn nghiên cứu của Hollowell $\mathrm{JG}$ trong khảo sát kiểm tra dinh dưỡng và sức khỏe quốc gia Hoa kỳ (NHANES) lần thứ 3 (suy giáp chiếm $4,6 \%$ với $0,3 \%$ suy giáp LS và $4,3 \%$ suy giáp DLS; cường giáp chiếm $1,3 \%$ với $0,5 \%$ cường giáp $L S$ và $0,7 \%$ cường giáp DLS) [6]. Có thể là vi nghiên cứu của chúng tôi tiến hành trên phụ nữ vô sinh, và suy giáp phổ biến ở phụ nữ gấp 5 đến 8 lần so với nam giới [6], [14].

Trong 3.2\% $\mathrm{BN}$ cường giáp có $0.5 \%$ cường giáp LS và $2,7 \%$ là cường giáp DLS. Kết quả này tương tự nghiên cứu của Joshi $J V$, Poppe $K$ với tỷ lệ vô sinh nguyên phát hoặc thứ phát liên quan đến cường giáp là $0,9 \%-5,8 \%[15]$. Và cao hơn nghiên cứu Garmendia Madariaga $\mathrm{A}$ và Hollowell JG. Trong NHANES lần thứ 3 của Hoa Kỳ là tỷ lệ mắc bệnh cường giáp là $0-8 \%$ ở châu Âu, và $1-3 \%$ ở Mỹ. Tỷ lệ mắc bệnh cường giáp LS là 0,5 tới $0,8 \%$ ở châu Âu, và $0-5 \%$ ở Mỹ [5] [6]. Điều này có thể do cường giáp DLS thường gặp hơn ở phụ nữ nhiều hơn[6].

Tỷ lệ suy giáp chiếm tỷ lệ lớn hơn cường giáp. Suy giáp chiếm $9.5 \%$, trong đó suy giáp lâm sàng là $0,5 \%$ và suy giáp dưới lâm sàng là $9 \%$. Kết quả này tương tự như nghiên cứu của Abalovich $M$ và cộng sự trên 244 phụ nữ vô sinh và 155 phụ nữ khỏe mạnh cho tỷ lệ suy giáp DLS là $13,9 \%$ phụ nữ vô sinh và 3,9\% ở phụ nữ khỏe mạnh[7]. Kết quả của nghiên cứu cũng tương tự các nghiên cứu trong các cuộc điều tra cộng đồng, tỷ lệ suy giáp LS thay đổi 0,1 - 2\% [8], [9], [10], [11], [12]. Tỷ lệ suy giáp DLS cao hơn, dao động 4 - $10 \%$ ở người lớn, có thể có tần suất cao hơn ở phụ nữ lớn tuổi [6], [8], [9], [13]. Tỷ lệ suy giáp DLS trong nghiên cứu của chúng tôi cao hơn nghiên cứu của $\mathrm{M}$. Arojoki và cộng sự (4\% tương đương $12 \mathrm{BN}$ trong 335 phụ nữ vô sinh có nồng độ TSH huyết thanh tăng từ 5,1 đến $32 \mathrm{mU} / \mathrm{l}$ ) [15] và cũng cao hơn nghiên cứu của Lincoln SR và cộng sự trong 704 nữ vô sinh có $2,3 \%$ BN có TSH tăng trên khoảng tham chiếu) [1].

Tỷ lệ mắc suy giáp cận lậm sàng ở phụ nữ hiếm muộn đã được báo cáo thay đổi từ $0,7 \%$ đến $43 \%[15]$. Theo nghiên cứu của Indu Verma có $26.7 \%$ bị suy giáp [ 17] và theo kết quả NHANES lần 3 của Hoa kỳ, 4,3\% trong số 16.533 người bị suy giáp DLS [6]. Tỷ lệ cường giáp DLS trong cộng đồng cũng dao động trong khoảng $0,7 \%$ đến $12,4 \%$.

Có lẽ những sự khác biệt này một phần là do sự khác biệt trong định nghĩa về giá trị TSH huyết thanh thấp hoặc cao và trong các quần thể $\mathrm{BN}$ được nghiên cứu và các rối loạn chức năng tuyến giáp DLS thường gặp hơn ở phụ nữ, người hút thuốc và người lớn tuổi [6], [14].

Các rối loạn trong nhóm $\mathrm{BN}$ nghiên cứu chủ yếu là cường giáp DLS và suy giáp DLS. Vì các triệu chứng ở giai đoạn này thường không rõ ràng và hầu hết $\mathrm{BN}$ không có biểu hiện triệu chứng. Việc chẩn đoán suy giáp DLS hoặc cường giáp DLS chỉ dựa trên xét nghiệm sinh hóa. Điều này cho thấy tầm quan trọng của việc tầm soát chức năng tuyến ở những $\mathrm{BN}$ vô sinh để phát hiện sớm những rối loạn dưới lâm sàng này và có biện pháp điều chỉnh kịp thời.

4.3. Mối liên quan giữa chức năng tuyến giáp với một số yếu tố nguy cơ ở nhóm BN nghiên cứu.

Trong nhóm BN nghiên cứu thì nhóm tuổi có rối loạn chức năng tuyến giáp thấp nhất là ở nhóm $<25$ tuổi và cao nhất ở nhóm $>35$ tuổi. Tỷ lệ rối loạn chức năng tuyến giáp ở 2 lứa tuổi này lần lượt là $1,4 \%$ và $5,4 \%$. Kết quả này tương tự các $\mathrm{NC}$ trong các cuộc điều tra cộng đồng, tần suất rối loạn chức năng tuyến giáp cao hơn ở phụ nữ lớn tuổi [5], [7], [8], [12]. Tỷ lệ rối loạn kinh nguyệt ở nhóm $\mathrm{BN}$ nghiên cứu là $32,7 \%$, trong đó $\mathrm{BN}$ có rối loạn chức năng tuyến giáp chiếm $4.6 \%$ và $\mathrm{BN}$ bình giáp chiếm $28,1 \%$.

Tỷ lệ rối loạn kinh nguyệt trong nhóm BN rối loạn chức năng tuyến giáp đặc biệt là $\mathrm{BN}$ suy giáp $(10 / 27 \mathrm{BN}$ chiếm $37 \%$ gồm $1 \mathrm{BN}$ cường giáp và $9 \mathrm{BN}$ suy giáp) cao hơn nhóm $\mathrm{BN}$ bình giáp (62/193 $\mathrm{BN}$ chiếm $32,1 \%)$. 
Tỷ lệ tăng mức prolactin máu của nhóm $\mathrm{BN}$ nghiên cứu là $24,4 \%$. Trong đó có $\mathrm{BN}$ rối loạn chức năng tuyến giáp chiếm $5,9 \%$ và $\mathrm{BN}$ bình giáp chiếm 18,5\%.

Tỷ lệ tăng mức prolactin máu trong nhóm $\mathrm{BN}$ rối loạn chức năng tuyến giáp $(13 / 28)$ chiếm $46,4 \%$ cao hơn ở nhóm bình giáp (41/194) chiếm $21,1 \%$.

Hai điều này cũng tương tự nghiên cứu của Lincoln $\mathrm{SR}$ và cộng sự nghiên cứu trên 704 nữ VS, tỷ lệ TSH tăng là $2,3 \%$, trong nhóm TSH tăng thì có $69 \%$ rối loạn chức năng rụng trứng[1]. Nghiên cứu của Talia Eldar-Geva cũng chỉ ra tỷ lệ mắc suy giáp DLS cao hơn ở những phụ nữ bị rối loạn rụng trứng $(20,5 \%)$ so với những phụ nữ có ngày rụng trứng bình thường $(8,3 \%)$ [18]

Có $77,9 \% \mathrm{BN}$ nghiên cứu không có tiền sử sản khoa nặng nề, $31,1 \%$ BN nhóm $\mathrm{BN}$ nghiên cứu có tiền sử sản khoa xấu là sảy thai, thai lưu $(15,3 \% \mathrm{BN}$ có tiền sử sảy thai, $9,9 \% \mathrm{BN}$ có tiền sử thai lưu và $5,9 \% \mathrm{BN}$ có cả xảy thai và thai lưu). Tỷ lệ sảy thai hoặc thai lưu ở nhóm có rối loạn chức năng tuyến giáp cao hơn nhóm $\mathrm{BN}$ bình giáp.

\section{KẾT LUẬN}

Qua nghiên cứu khảo sát chức năng tuyến giáp ở phụ nữ vô sinh, tuổi từ 18- 45 đến khám và điều trị tại Trung tâm hỗ trợ sinh sản và mô ghép Bệnh viện Trường Đại học $\mathrm{Y}$ Hà Nội và Trung tâm Hỗ trợ sinh sản Bệnh viện Phụ sản Trung ương từ tháng 01 năm 2018 đến tháng 8 năm 2020, chúng tôi rút ra kết luận sau:

\subsection{Tỷ lệ rối loạn chức năng tuyến giáp} ở phụ nữ vô sinh trên nhóm $\mathrm{BN}$ nghiên cứu:

- Tỷ lệ rối loạn chức năng tuyến giáp ở nhóm $\mathrm{BN}$ nghiên cứu là 12,7 :

+ Cường giáp chiếm $3,2 \%$, cường giáp LS chiếm $0,5 \%$, cường giáp DLS chiếm $2,7 \%$

+ Suy giáp chiếm $9,5 \%$, suy giáp LS chiếm $0,5 \%$, suy giáp DLS chiếm $9 \%$

- Các rối loạn trong nhóm BN nghiên cứu chủ yếu là cường giáp DLS và suy giáp DLS

5.2 Mối liên quan giữa rối loạn chức năng tuyến giáp với một số yếu tố liên quan ở nhóm BN nghiên cứu:
- Nhóm tuổi > 35 là nhóm BN nghiên cứu có rối loạn chức năng tuyến giáp nhiều nhất.

- Tỷ lệ rối loạn kinh nguyệt ở nhóm $\mathrm{BN}$ nghiên cứu là $32,7 \%$. Tỷ lệ rối loạn kinh nguyệt trong nhóm $\mathrm{BN}$ rối loạn chức năng tuyến giáp $(37 \%)$ cao hơn nhóm $\mathrm{BN}$ bình giáp $(32,1 \%)$. Có $31,1 \% \mathrm{BN}$ nhóm nghiên cứu có tiền sử sản khoa xấu (sảy thai, thai lưu hoặc có cả sảy thai và thai lưu). Trong đó $4,7 \% \mathrm{BN}$ suy giáp và $0,5 \% \mathrm{BN}$ cường giáp.

- Tỷ lệ $\mathrm{BN}$ có mức prolactin cao ở nhóm $\mathrm{BN}$ nghiên cứu là $24,4 \%$. Tỷ lệ tăng mức prolactin máu trong nhóm có rối loạn chức năng tuyến giáp (13/28 BN chiếm 46,4\%) cao hơn nhóm $\mathrm{BN}$ bình giáp (41/194 $\mathrm{BN}$ chiếm $21,1 \%)$.

\section{TÀI LIẾU THAM KHẢO}

1. Lincoln R, Ke RW, Kutteh WH. Screening for hypothyroidism in infertile women. $\mathbf{J}$ Reprod Med. 1999;44:4557. [PubMed] [Google Scholar

2. Krassas GE. Thyroid disease and female reproduction. Fertil Steril. 2000;74:106370. [PubMed] [Google Scholar

3. The Practice Committee of the American Society for Reproductive Medicine, authors. Optimal evaluation of the infertile female. Fertil Steril. 2006;86(5 suppl):S264-S267.[PubMed] [Google Scholar].

4. Canaris GJ, Manowitz NR, Mayor G, Ridgway EC. The Colorado thyroid disease prevalence study. Arch Intern Med 2000; 160:526.

5. Garmendia Madariaga A, Santos Palacios S, Guillén-Grima F, Galofré JC. The incidence and prevalence of thyroid dysfunction in Europe: a meta-analysis. $\mathbf{J}$ Clin Endocrinol Metab. 2014;99:92331. [PubMed] [Google Scholar]

6. Hollowell JG, Staehling NW, Flanders WD, et al. Serum TSH, T(4), and thyroid antibodies in the United States population (1988 to 1994): National Health and Nutrition Examination Survey (NHANES III). J Clin Endocrinol Metab 2002; 87:489. 
7. Abalovich M, Mitelberg L, Allami C, et al. Subclinical hypothyroidism and thyroid autoimmunity in women with infertility. Gynecol Endocrinol 2007; 23:279.

8. Tunbridge WM, Evered DC, Hall R, et al. The spectrum of thyroid disease in a community: the Whickham survey. Clin Endocrinol (Oxf) 1977; 7:481.

9. Vanderpump MP, Tunbridge WM, French $\mathrm{JM}$, et al. The incidence of thyroid disorders in the community: a twentyyear follow-up of the Whickham Survey. Clin Endocrinol (Oxf) 1995; 43:55.

10. Vanderpump MP, Tunbridge WM. The epidemiology of thyroid diseases. In: The thyroid: A fundamental and clinical text, 8th, Braverman LE, Utiger RD (Eds), Lippincott Williams and Wilkins, Philadelphia 2000. p.467.

11. Canaris GJ, Manowitz NR, Mayor G, Ridgway EC. The Colorado thyroid disease prevalence study. Arch Intern Med 2000; 160:526.

12. Aoki Y, Belin RM, Clickner R, et al. Serum TSH and total T4 in the United States population and their association with participant characteristics: National Health and Nutrition Examination Survey (NHANES 1999-2002). Thyroid 2007; 17:1211.

13. Walsh JP, Bremner AP, Feddema P, et al. Thyrotropin and thyroid antibodies as predictors of hypothyroidism: a 13-year, longitudinal study of a community-based cohort using current immunoassay techniques. J Clin Endocrinol Metab 2010; 95:1095.
14. Belin RM, Astor BC, Powe NR, Ladenson PW. Smoke exposure is associated with a lower prevalence of serum thyroid autoantibodies and thyrotropin concentration elevation and a higher prevalence of mild thyrotropin concentration suppression in the third National Health and Nutrition Examination Survey (NHANES III). J Clin Endocrinol Metab 2004; 89:6077.

15. Poppe K, Velkeniers B, Glinoer D. Thyroid disease and female reproduction. Clin Endocrinol (Oxf) 2007;66:309-321. [PubMed] [Google Scholar

16. M. Arojoki,V. Jokimaa,A. Juuti,P. Koskinen,K. Irjala \&L. Anttila, Hypothyroidism among infertile women in Finland , Gynecological Endocrinology Volume 14, 2000 - Issue 2, Pages 127-131 | Published online: 05 Aug 2009

17. Dr. Indu Verma, Department of Biochemistry, Dayanand Medical College and Hospital, Ludhiana, Punjab, India Prevalence of hypothyroidism in infertile women and evaluation of response of treatment for hypothyroidism on infertility (Int J Appl Basic Med Res. 2012 Jan-Jun; 2(1): 17-19.

18. Talia Eldar-Geva, Subclinical hypothyroidism in infertile women: The importance of continuous monitoring and the role of the thyrotropin-releasing hormone stimulation test, Journal Gynecological Endocrinology, Volume 23, 2007 - Issue 6. 